\title{
Reforma Tributária Necessidade de um Novo Sistema
}

\section{Ives Gandra da Silva Martins}

Professor Emérito da Universidade Mackenzie e da Escola de Comando e Estado Maior do Exército, Presidente do Conselho de Estudos Jurídicos da Federação do Comércio do Estado de São Paulo.

Esta breve exposição, pretendo dividi-la em três partes, ou seja, analisar, de início, a reforma que se fez em dezembro de 2003, de pouca monta (E.C. no 42/03); em seguida examinar o principal problema de integração dos espaços comunitários, que é o fato de termos o ICMS regionalizado, para, ao final, apresentar minha proposta de reforma tributária, levada pelo Deputado Germano Rigotto à não ocorrida Revisão Constitucional de 1993, mas que vale a pena ser repensada.

\section{-I-}

A Emenda Constitucional no $42 / 03$ foi mais um remendo que a Constituição recebeu do Congresso Nacional, com poderes constituintes derivados, que hoje conformam permanente "contribuição de pioria" ao texto aprovado em 1988.

Sua origem reside na PEC 41/03, que sofreu alterações profundas, desde sua apresentação e discussão, na Câmara e no Senado, com algumas amputações necessárias (progressividade do imposto sobre operações de transmissão imobiliária não onerosas e imposto sobre transmissão imobiliária onerosa) e alterações de ocasião. De rigor, reduziu-se à prorrogação da CPMF, à desvinculação da receita da União, à transferência de parte da CIDE para Estados e Municípios, além da inserção de alguns dispositivos "explicitadores" 
do que já existia no texto constitucional. Postergou-se, por outro lado, o enfrentamento do grande desafio, que é equacionar os problemas provocados pelo ICMS, imposto de vocação nacional, regionalizado no país, - experiência única no mundo - com péssimos resultados colhidos até aqui, no que concerne à técnica de valor agregado.

Passo a elencar as modificações, com rápidos comentários.

Foi acrescentada a alínea " $d$ " ao inciso III do art. 146 da Constituição Federal, com a diç̧ão seguinte:

"Art. 146 Cabe à lei complementar: ... III. estabelecer normas gerais em matéria de legislação tributária, especialmente sobre: ... d) definição de tratamento diferenciado e favorecido para as microempresas e para as empresas de pequeno porte, inclusive regimes especiais ou simplificados no caso do imposto previsto no art. 155, II, das contribuições previstas no art. 195, I e $\xi \xi 12$ e 13, e da contribuição a que se refere o art. 239".

- Trata-se de artigo explicitador do art. 179 da lei suprema, que já continha, de forma genérica, tal disposição, estando assim redigido:

"A União, os Estados, o Distrito Federal e os Municipios dispensarão às microempresas e às empresas de pequeno porte, assim definidas em lei, tratamento juridico diferenciado, visando a incentivá-las pela simplificação de suas obrigações administrativas, tributárias, previdenciárias e creditícias, ou pela eliminação ou redução destas por meio de lei".

Meu receio é de que aquilo que já se fazia por lei ordinária fique agora sujeito a regime de lei complementar. Uma vantagem, entretanto, decorre da disposição. É que a lei complementar obrigará União, Estados, Distrito Federal e Municipios, devendo, pois, voltar-se, principalmente, ao ICMS e às contribuições sociais.

O parágrafo único, com a redação que se segue, acrescenta:

"§ único - A lei complementar de que trata o inciso III, " $d$ ", também poderá instituir um regime único de arrecadação dos impostos e contribuições da União, dos Estados, do Distrito Federal e dos Municipios, observado que: I- será opcional para o contribuinte; II - poderão ser estabelecidas condições de enquadramento diferenciadas por Estado; III- o recolhimento será unificado e centralizado e a distribuição da parcela 
de recursos pertencentes aos respectivos entes federados será imediata, vedada qualquer retenção ou condicionamento; IVa arrecadação, a fiscalização e a cobrança poderão ser compartilhadas pelos entes federados, adotado cadastro nacional único de contribuintes".

A norma beneficia mais o fisco do que o contribuinte, pois, a título de favorecer o regime único de arrecadação com partilha da receita para as entidades federativas, no que concerne às empresas de pequeno porte, permitirá uma fiscalização múltipla, objetivando - exercício do controle das 3 esferas da Federação, o que gerará dificuldades muito superiores às que existem na atualidade. É possível que se verifique um aumento do arbítrio e de desvios como a "concussão" e "corrupção", visto que tal regime autorizará o exercício do poder fiscalizatório por todas as esferas e de todas as entidades federativas ao mesmo tempo. Uma empresa que trabalhe com 10 Estados e 50 Municípios, poderá sofrer 60 fiscalizações e não apenas aquela do Município e do Estado onde está sediada.

O artigo 146-A é positivo, tendo a seguinte redação:

"Lei Complementar poderá estabelecer critérios especiais de tributação, com o objetivo de prevenir desequilibrios da concorrência, sem prejuizo da competência de a União, por lei, estabelecer normas de igual objetivo",

Objetiva evitar concorrência predatória, através de incentivos fiscais abusivos, que possam desequilibrar a livre competição entre empresas de diversos Estados ou Municípios, ou mesmo entre empresas conformadas por grupos diversos, mas sob controle único.

Poderá, entretanto, facultar o arbítrio fiscal, alargando o espectro de atuação da polêmica e é, a meu ver, inconstitucional, norma anti-elisão (L.C. 104/00).

$O$ § $1^{\circ}$ do art. 149 recebeu redação ofertada pela E.C. n. 41/03 (previdência), estabelecendo critérios para a cobrança de contribuição de servidores dos Estados, D.F., Municípios, estando assim redigido:

"§ 10 Os Estados, o Distrito Federal e os Municípios instituirão contribuição, cobrada de seus servidores, para o custeio, em beneficio destes, do regime previdenciário de que trata 0 art. 40, cuja alíquota não será inferior à da contribuição dos servidores titulares de cargos efetivos da União". 
O § $2^{\circ}$ do art. 149 , inciso II, alargou o campo de incidência das contribuições sociais e de intervenção do domínio econômico. Com relação a estas últimas, nenhuma delas ostenta perfil interventivo para regular setores descompassados na economia, tendo por objetivo apenas ensejar o aumento da arrecadação. São, pois, meros rótulos. Tem, a norma, a seguinte diç̧ão:

"As contribuições sociais e de intervenção no domínio econômico de que trata o "caput" deste artigo: .... II. incidirão também sobre a importação de produtos estrangeiros ou serviços; ...".

O argumento de que teria por finalidade equiparar os produtos importados ou serviços prestados no exterior aos que se produzem ou se prestam no Brasil perde consistência, num pais de juros elevados, pela antecipação de receita que implicará, no âmbito das contribuições não cumulativas, considerável aumento.

Dispositivo a ser elogiado é o da letra " $c$ " do artigo 150, com o discurso que se segue:

"Art. 150 Sem prejuizo de outras garantias asseguradas ao contribuinte, é vedado à União, aos Estados, ao Distrito Federal e aos Municipios:

.... c) antes de decorridos 90 dias da data em que haja sido publicada a lei que os instituiu ou aumentou, observado o disposto na alinea " $b$ "'."

Acresce-se, pois, ao princípio da anterioridade, o da denominada "noventena". Assim, mesmo que promulgada em 31/12, uma lei prevendo aumento ou instituição de tributo não excepcionado do princípio, só entrará em vigor em 31 de março - ou 30, se o ano for bissexto.

.0 \& $1^{\circ}$ do artigo 150 apresenta, todavia, " $n$ " exceções, estando assim redigido:

"A vedação do inc. III, " $b$ ", não se aplica aos tributos previstos nos arts. 148, I, 153, I, II, IV e V; e 154, II, e a vedação do inc. III, " $C$ ", não se aplica aos tributos previstos nos arts. 148, I, 153, I, II, III e V, e 154, II, nem à fixação da base de cálculo dos impostos previstos nos arts. 155, III, e 156, I".

Por erro de promulgação, esqueceu, o constituinte, de acrescentar o inciso I, letra " $b$ ", do $\S 4^{\circ}$ do art. 177 , assim redigido: 
"A lei que instituir contribuição de intervenção no domínio econômico relativa às atividades de importação ou comercialização de petróleo e seus derivados, gás natural e seus derivados $e$ álcool combustivel deverá atender aos seguintes requisitos:

I. a alíquota da contribuição poderá ser: ... b) reduzida $e$ restabelecida por ato do Poder Executivo, não se Ihe aplicando $o$ disposto no art. 150, III, b",

que também introduz uma exceção à contribuição de intervenção no domínio econômico a que me refiro.

Como se percebe, há mais regras de exceção do que regra geral, com o que o constituinte dá com uma mão e retira com a outra o benefício outorgado.

O § 30, inciso IV, do artigo 153 contém, por outro lado, novidade prógramática, sendo sua diç̧ão a que segue:

"§ 300 imposto previsto no inc. IV: ...... IV. terá reduzido seu impacto sobre a aquisição de bens de capital pelo contribuinte do imposto, na forma da lei".

De rigor, dependerá de lei a redução do nivel impositivo do IPI sobre a aquisição de bens de capital, como forma de incentivar a produção nacional de tais imprescindiveis bens para o desenvolvimento do país, valendo, também, para as máquinas e equipamentos importados.

Espera-se que a lei seja rapidamente publicada. E será lei ordinária federal.

O § 40, inciso III, introduz novidade, estando assim redigido: "O imposto previsto no inc. VI do "caput". ... III. será fiscalizado e cobrado pelos Municipios que assim optarem, na forma da lei, desde que não implique redução do imposto ou qualquer outra forma de renúncia fiscal".

O -município com capacidade para arrecadar o tributo ficará com a receita do ITR, desde que não reduza a alíquota estabelecida por lei federal ou promova qualquer forma de renúncia fiscal.

A intenção é boa, pois permite que se utilize o tributo de forma nacional como instrumento de política agrária, mas também beneficia os municípios com capacidade de arrecadá-lo (que tenham, pois, máquina administrativa para tanto), que ficarão com o produto de sua arrecadação. 
.0 artigo $155, \S 20$, inc. $X$, letra "a", foi também alterado, tendo a seguinte diç̧ão:

"\$ $2^{\circ} O$ imposto previsto no inc. II atenderá ao seguinte: ... X - não incidirá: a) sobre operações que destinem mercadorias para o exterior, nem sobre serviços prestados a destinatários no exterior, assegurada a manutenção e o aproveitamento do montante do imposto cobrado nas operações e prestações anteriores;".

A alteração tornou definitiva, no âmbito do ICMS, a "não exportação de tributos", já contemplada na lei complementar $n^{\circ} 87 /$ 96, porém de duvidoso significado pois, a título de regulamentar quais seriam os produtos semi-elaborados não sujeitos ao ICMS, declarou que não havia nenhum.

A alteração é, portanto, positiva.

A letra " $d$ ", do mesmo inciso, foi introduzida como se segue:

"d) nas prestaçôes de serviço de comunicação nas modalidades de radiodifusão sonora e de sons e imagens de recepção "livre e gratuita".

A norma é boa e atende à discussão que se trava sobre se seriam ou não, tais operações, alcançadas pelo tributo. Corrige, e para melhor, a omissão anterior, ensejadora de dúvidas e discussões.

$0 \S 60$, introduzido no artigo 155 , acerca do imposto sobre a propriedade de veículos automotores (previsto no inciso III), está assim redigido:

"O imposto previsto no inciso III: I. terá aliquotas mínimas fixadas pelo Senado Federal; II. poderá ter alíquotas diferenciadas em função do tipo e utilização".

A meu ver, também foi positiva a introdução, visto que tem por objetivo eliminar a guerra fiscal entre os Estados. A alíquota mínima fixada pelo Senado evita que os veículos de um Estado sejam licenciados em outro, por força de aliquota menor.

Elemento positivo da reforma.

- O artigo 195, inciso IV, introduziu nova forma de tributação para as contribuições sociais, a saber:

"Art. 195 A seguridade social será financiada por toda a sociedade, de forma direta e indireta, nos termos da lei, mediante 
recursos provenientes dos orçamentos da União, dos Estados, do Distrito Federal e dos Municipios, e das seguintes contribuições sociais: .... IV. do importador de bens ou serviços do exterior, ou de quem a lei a ele equiparar".

Já comentei o dispositivo anteriormente. Quando a contribuição for cumulativa, representa efetiva elevação da carga tributária. Foi editada, para torná-la exigivel, a M.P. 164/03 já transformada em lei.

O $\S 12^{\circ}$, do respectivo artigo, tem a seguinte redação:

"A lei definirá os setores de atividade econômica para os quais as contribuições incidentes na forma dos incisos $I$, " $b$ "; e IV do "caput", serão não-cumulativas".

Abre, pois, a faculdade de serem as contribuições não cumulativas. Na redação que foi veiculada (mera faculdade), o § $12^{\circ}$ é despiciendo. Se não existisse, nem por isto seria proibida a adoção da não-cumulatividade para as contribuições. $O$ próprio governo antes da promulgação da referida emenda - já veiculara a M.P. 135/03, introduzindo a não-cumulatividade - a meu ver, inconstitucional por outros motivos (inconstitucionalidades formais e materiais) e não por este (introdução da não-cumulatividade para a Cofins).

E, por fim, 0 ato complementar das disposições transitórias a Constituição Brasileira, com 48 emendas, é a mais transitória que conheço, razão pela qual a considero uma Constituição provisória foi acrescido de 5 novos artigos (89 a 94), quatro, assim redigidos, dedicados ao sistema tributário:

"Art. 90 - O prazo previsto no «caput" do art. 84 deste Ato das Disposições Constitucionais Transitórias fica prorrogado até $31 / 12 / 2007$.

$51^{\circ}$ - Fica prorrogada, até a data referida no «caput» deste artigo, a vigência da Lei 9.311, de 24/10/96, e suas alteraçôes. $\$ 22^{\circ}$ - Até a data referida no «caput"deste artigo, a alíquota da contribuição de que trata 0 art. 84 deste Ato das Disposições Constitucionais Transitórias será de trinta e oito centésimos por cento.

Art. 91 - A União entregará aos Estados e ao Distrito Federal o montante definido em lei complementar, de acordo com critérios, prazos e condições nela determinados, podendo conside- 
rar as exportações para o exterior de produtos primários $e$ semi-elaborados, a relação entre as exportações e as importações, os créditos decorrentes de aquisições destinadas ao ativo permanente e a efetiva manutenção e aproveitamento do crédito do imposto a que se refere 0 art. $155,2^{\circ}, X$, «a».

$\xi 1^{\circ}$ - Do montante de recursos que cabe a cada Estado, setenta e cinco por cento pertencem ao próprio Estado, e vinte e cinco por cento, aos seus Municípios, distribuidos segundo os critérios a que se refere 0 art. 158, parágrafo único, da Constituição.

$\xi 2^{\circ}$ - $A$ entrega de recursos prevista neste artigo perdurará, conforme definido em lei complementar, até que o imposto a que se refere $o$ art. 155, II, tenha o produto de sua arrecadação destinado predominantemente, em proporção não inferior a oitenta por cento, ao Estado onde ocorrer o consumo das mercadorias, bens ou servicos.

$\xi 3^{0}$ - Enquanto não for editada a lei complementar de que trata o «caput», em substituição ao sistema de entrega de recursos nele previsto, permanecerá vigente o sistema de entrega de recursos previsto no art. 31 e Anexo da Lei Complementar 87, de 13/09/96, com a redação dada pela Lei Complementar 115, de 26/12/2002.

$\$ 4^{\circ}$ - Os Estados e o Distrito Federal deverão apresentar a União, nos termos das instruções baixadas pelo Ministério da Fazenda, as informações relativas ao imposto de que trata $o$ art. 155, II, declaradas pelos contribuintes que realizarem operações ou prestações com destino ao exterior.

Art. 92 - São acrescidos dez anos ao prazo fixado no art. 40 deste Ato das Disposições Constitucionais Transitárias.

Art 93 - A vigência do disposto no art. 159, III, e $\xi 40$, iniciará somente após a edição da lei de que trata o referido inciso III. Art. 94-Os regimes especiais de tributação para microempresas e empresas de pequeno porte próprios da União, dos Estados, do Distrito Federal e dos Municípios cessarão a partir da entrada em vigor do regime previsto no art. 146, III, "d", da Constituição".

Prorrogam-se, por tais disposições, a CPMF e a desvinculação da receita da União; garante-se aos Estados compensação pela per- 
da da incidência do ICMS nas exportações imunes dos semi-elaborados, cabendo aos Municípios parte desta compensação (25\%); admite-se que, um dia, adotar-se-á o polêmico regime de destino, até lá continuando a prevalecer o sistema atual; aumentam-se as exigências burocráticas para as exportações, acrescentando às existentes, aquelas que os Estados irão obter junto aos contribuintes para informar a União, na busca de maior partilha; prorroga-se por mais 10 anos o prazo do artigo 40, mantendo-se os incentivos da Zona Franca (até 2023); condiciona-se à edição de lei o repasse da contribuição de intervenção no domínio econômico para Estados e Municípios, no percentual de 25\%; e declara-se o esgotamento de toda a legislação que hoje beneficia as empresas de pequeno porte, tão logo editada a lei complementar a que se refere o artigo 146, inciso III, letra " $\mathrm{d}$ ", já comentado anteriormente.

De rigor, a reforma tributária foi pífia. Pequenos remendos, o sempre previsivel aumento de carga tributária, quando se fala em reforma tributária, e a permanência de quase todos os grandes problemas que, desde 1988 , prejudicam a vida dos contribuintes.

Os artigos comentados, que propiciam o aumento da Cofins, CIDE e outras incidências - por um espectro mais lato de imposição instituído - certamente trarão, para o futuro, mais complicações na vida dos contribuintes e, certamente, maior carga, para amarrar o desenvolvimento nacional, que já hoje não permite que o Brasil evolua no mesmo nível de outros países emergentes, como China, Índia e Rússia, com crescimento superior a $8 \%$ anuais.

Não sem razão, graças à permanente "contribuição de pioria" que a reforma tributária vem representando até aqui, o Brasil caiu de $8^{a}$. economia do mundo - lugar obtido nos tempos do regime autoritário para $15^{\mathrm{a}} \mathrm{em} 2003$, prevendo-se, em face do excesso de burocracia, do excesso de tributos e dos excessivos juros, que dias piores virão.

\section{-II-}

Nas duas primeiras décadas do século XXI, deverá ocorrer nitida aproximação dos sistemas tributários de todo o mundo.

No momento, tal aproximação se dá, na esmagadora maioria dos países que participam de algum sistema de integração comunitária (Zona Franca, União Aduaneira, Mercado Comum ou Comuni- 
dade Econômica e/ou Política), através do imposto sobre valor agregado que, nas relações entre países que ocupam tais espaços, faz o papel de tributo integrativo, de regulação da concorrência não predatória e de satisfação das necessidades das burras estatais.

O sistema aduaneiro, do ponto de vista da política tributária, não oferece problemas maiores, na medida em que ou é protetor de cada país, nas suas relações econômicas não integradas, ou funciona a partir das soluções de zona franca, como um elemento de segurança de mercados acordados, quando não apenas de redução de suas barreiras, para permitir que os produtos entre países negociantes escoem-se em condições de vantagem.

Não chega a ser um escudo protetor, nos sistemas de zona franca, pois nele há apenas uma redução de tarifas acordadas entre os Estados signatários do acordo, mas já o é, nas denominadas tarifas externas comuns, que servem de blindagem contra a entrada de produtos e serviços de países não signatários, tarifas estas só eleváveis ou redutiveis mediante acordo entre as nações participantes do bloco.

Por ser a tarifa aduaneira, de rigor, um tributo não de natureza arrecadatória, como é o IVA, mas de natureza regulatória de mercados, sua importância é grande, na conformação dos espaços comunitários, mas indiscutivelmente menor - após tal conformação do que a do imposto sobre o valor agregado, este o imposto comunitário por excelência, ou, se desejarem os formalistas (que só admitem a terminologia para os espaços já perfilados em "comunidades"), é o imposto por excelência dos países ocupantes de espaços plurinacionais acordados.

Para a configuração deste tributo, há uma evidente aproximação de técnicas de cobrança e de desenho das hipóteses de imposição, visto que quanto maior a proximidade entre os sistemas internacionais, tanto melhor se fará o fluxo econômico, dentro de espaços formados.

Não é uma verdade absoluta que tal imposto - a vedete das áreas supranacionais - seja, necessariamente, aquele a ser adotado pelos paises que decidam empreender uma integração maior com seus vizinhos, sendo talvez o NAFTA o exemplo mais claro de espaço em que sua adoção não se dá, visto que os Estados Unidos não 
têm o IṾA em seu sistema de tributação, em verdade, o que oferta insuperável problema de integração, maior do que a mera redução tarifária que o Acordo permite.

É de se lembrar, outrossim, que nos espaços não só europeu, como do cone sul-americano (União Européia e Mercosul), a circulação é livre tanto de bens como de pessoas, o mesmo não ocorrendo no acordo do Canadá, México e Estados Unidos (NAFTA), em que canadenses e americanos livremente transpõem suas fronteiras, mas não os mexicanos. Poder-se-á dizer que transitória limitação semeIhante existe, no espaço europeu, para os novos países aderentes (10) e para os que pretendem aderir (2), mas a própria integração ampla está projetada para o futuro $\longrightarrow$ que não tem horizontes tão claros para acontecer no espaço aberto para o continente norte da América. Assim, NAFTA é, apenas, um acordo tarifário sofisticado.

Em verdade, as dificuldades dos Estados Unidos decorrem de sua Federação. Na sua conformação, o constituinte de 1787 deixou claro que essa forma de Estado fora dotada com não poucas vacilações, visto que, durante 11 anos, não sabia a nova nação se deveria ser uma confederação de países ou uma federação de Estados.

E o certo é que a federação americana é uma "quase confederação". Outorga tal autonomia aos Estados, que têm eles legislação própria nos campos civil, penal, processual etc., característica que a maior parte das federações não possui, como é o caso, por exemplo, no Cone Sul, da Argentina e do Brasil.

É de se compreender, pois, que a federalização de um imposto circulatório, à semelhança do IVA argentino ou alemão, com partilha entre as unidades federativas, não é tarefa factivel enquanto não se avança -o que considero impossivel nas próximas décadas - para outras integrações legislativas dentro da Federação americana. No Nafta, não será fácil, portanto, o caminho da integração via IVA.

O Brasil sofre de idêntico problema, pois regionalizou o IVA, dividindo-se em 5 imposições circulatórias, todas, em parte, não cumulativas (PIS, COFINS, ICMS, ISS, IPI).

Mesmo para aquelas imposições em que o governo impõe a não cumulatividade (IPI e ICMS) e não apenas torna optativa sua adoção (COFINS e PIS expressamente e implicitamente ISS), esta não-cumulatividade é afastada por incidências monofásicas, tribu- 
tando-se antecipadamente, na própria origem, mediante a figura da substituição tributária para frente, toda a cadeia produtiva, ou instituindo-se a incidência monofásica para determinados produtos, sem se levar em consideração o valor futuro da operação. Há, ainda, o processo da substituição tributária para trás em que, também mediante a eleição de um substituto ou da figura da imunidade, desoneram-se as operações anteriores, como ocorre nas operações interestaduais com combustiveis.

Enfim, a multiplicação de incidências circulatórias na Federação brasileira, com incidência federal do IPI sobre a produção de bens, ICMS estadual sobre sua circulação e ISS municipal sobre os serviços, excluídos os de transporte e comunicação, de âmbito estadual, além das contribuições sociais, cuja finalidade é mais arrecadatória que social (PIS e COFINS), - torna o sistema tributário brasileiro de difícil integração com o IVA, hoje consagrado na Argentina, Uruguai e Paraguai, países signatários do Mercosul, como imposto centralizado.

Acresce-se a questão de não poder a União (Poder Público), outorgar, por lei, incentivos fiscais estaduais e municipais, em virtude de vedação constitucional. Assim, a evolução do acordo tributário integrativo entre os países do Mercosul terá que necessariamente passar por uma reforma constitucional no Brasil, visto que os 3 outros paises já têm o IVA centralizado, até mesmo em nivel federativo, como ocorre com a Argentina.

O certo é que o IVA é o primeiro e mais relevante tributo de integração comunitária, nada obstante os problemas que oferta. Hoje, por exemplo, se percebe a dificuldade de adoção de um sistema de origem na arrecadação do tributo incidente sobre mercadoria ou serviço destinado a outro Estado, visto que a existência de uma câmara de compensações entre Estados importadores líquidos e exportadores líquidos não é de fácil organização. Depende de que todos os países empreendam esforço idêntico, tanto para arrecadar receita própria quanto para arrecadar o que pertence a outro membro da comunidade, devendo-lhe ser remetido.

A Europa, que evoluiu mais do que qualquer país na conformação de um IVA nacional (todas as nações fazem o que quiserem com este tributo dentro de suas fronteiras) e comunitário (com re- 
gras acordadas entre os países signatários dos diversos tratados, desde 0 . de Roma), ainda precisa aperfeiçoar mais a sistemática implementada, para que possa substituir a arrecadação no destino pela arrecadação na origem com repasse ao país de destino, objetivo perseguido desde o Tratado de Maastrich.

No NAFTA, a solução canadense de regularização parcial é menos complexa, para uma integração futura, do que o sistema do "tax on sale" dos americanos; e, no Mercosul, a regionalização do ICMS - principal tributo brasileiro - praticamente inviabiliza um sistema comum integrativo.

\title{
-III-
}

Passo, agora, a expor a Proposta de Emenda Constitucional que fiz, em 1990, de um novo sistema tributário.

\section{Título VI}

Da Tributação e do Orçamento

Capítulo 1

Do Sistema Tributário Nacional

\author{
Seção 1 \\ Dos Principios Gerais
}

"Art. 145. A União, os Estados, o Distrito Federal e os Municipios poderão instituir os seguintes tributos:

I. impostos;

II. taxa pela utilização de serviços públicos específicos e divisiveis prestados ao contribuinte, sempre que o contribuinte não tenha alternativa válida para deles prescindir, limitada ao custo da prestação;

III. contribuição de melhoria decorrente de obras públicas, que impliquem valorização do imóvel e no limite de seu custo. Art. 146. Os impostos serão graduados segundo a capacidade contributiva dos cidadãos, residentes e outros que a lei determinar, respeitados os direitos e garantias individuais e proibido o confisco. 
Parágrafo único. É vedada a utilização do mesmo fato gerador para mais de um tributo, ou as taxas não poderão ter base de cálculo própria de imposto.

Art. 147. Cabe à lei complementar estabelecer normas gerais em matéria tributária, assim como regular as limitações ao poder de tributar e dirimir confitos entre os poderes tributantes. Art. 148, A União, mediante lei complementar, poderá instituir empréstimos compulsórios para atender despesas extraordinárias decorrentes de calamidade publica ou de guerra externa. Art. 149. Compete exclusivamente à União instituir uma contribuição social incidente sobre movimentação financeira para atender a seguridade social, nos termos da lei complementar.

\section{Seção II \\ Das limitações do poder de tributar}

Art. 150. Sem prejuizo de outras garantias asseguradas ao contribuinte, é vedado à União, aos Estados, ao Distrito Federal e aos Municipios:

I. exigir ou aumentar tributo sem lei que o estabeleça;

II. instituir tratamento desigual entre contribuintes que se encontrem em situação equivalente, proibida qualquer distinção em razão de ocupação profissional ou função por eles exercida, independentemente da denominação juridica dos rendimentos, títulos ou direitos;

III. cobrar tributos:

a) em relação a fatos geradores ocorridos antes do início da vigência da lei que os houver instituido ou aumentado;

b) no mesmo exercício financeiro em que haja sido publicada a lei que os instituiu ou aumentou, respeitada a determinação do art. 165, \&2, ${ }^{\circ}$;

c) antes de decorridos 90 dias da data em que haja sido publicada a lei que os instituiu ou aumentou, observado o disposto na alinea " $b$ ";

IV. utilizar o tributo com efeito de confisco;

$V$. estabelecer limitações ao tráfego de pessoas ou bens;

$V I$. instituir impostos sobre: 
a) patrimônio, rendas e circulação de bens e serviços, uns dos outros;

b) templos de qualquer culto;

c) patrimônio, renda ou serviços dos partidos políticos, inclusive suas fundações, das entidades sindicais dos trabalhadores e empregadores, das instituições de educação e de assistência social, sem fins lucrativos;

d) livros, jornais, periódicos, assim como papel, insumos, máquinas e equipamentos destinados à sua impressão, publicidade $e$ anúncios neles veiculados;

e) livros, jornais, periódicos por meios eletrônicos ou audiovisuais, inclusive textos destinados à educação, formação $e$ informação das pessoas de forma não periódica.

$\S 1 . \circ$ A vedação do inc. III, "b", não se aplica aos impostos previstos no art. 153, inciso I, respeitado o disposto no art. $165, \xi 2 .^{\circ}$.

S 2. ${ }^{\circ}$. A vedação do inc. VI, "a", é extensiva às autarquias e às fundaçōes instituídas e mantidas pelo Poder Público, no que se refere ao patrimônio, à renda e à circulação de bens e serviços vinculados às suas finalidades essenciais ou d̀s delas decorrentes.

\$3 $3^{\circ}$. As vedações do inciso VI, "a", e do parágrafo anterior não se aplicam ao patrimônio, à renda e à circulação de bens $e$ serviços relacionados com exploração de atividades econômicas regidas pelas normas aplicáveis a empreendimentos privados, ou em que haja contraprestação ou pagamento de preços ou tarifas pelo usuário, nem exonera o promitente comprador da obrigação de pagar imposto relativamente ao bem imóvel. $\xi 4^{\circ}$. As vedaçôes expressas no inciso $V I$, alíneas " $b$ " $e$ " $c$ ", compreendem somente o patrimônio, a renda e a circulação de bens e serviços relacionados com as finalidades essenciais das entidades nelas mencionadas.

Art. 151. É vedado à União:

I. instituir tributo que não seja uniforme em todo o território nacional ou que implique distinção ou preferência em relação a Estado, ao Distrito Federal ou a Municipio, em detrimento de outro, admitida a concessão, nos impostos, de incentivos 
destinados a promover o equilibrio do desenvolvimento sócioeconômico entre as diferentes regiôes do pais;

II. tributar por imposto a renda das obrigações da dívida pública dos Estados, do Distrito Federal e dos Municípios, bem como a remuneração e os proventos dos respectivos agentes públicos, em niveis superiores aos que fixar para suas obrigações e para seus agentes.

PARÁGRAFO ÚNICO. A União poderá celebrar tratados internacionais tributários, estabelecendo incentivos e estímulos tributários estaduais e municipais.

Art. 152. É vedado aos Estados e ao Distrito Federal estabelecer diferença tributária entre bens e serviços, de qualquer natureza, em razão de sua procedência ou destino.

Seção III

Os impostos da União

Art. 153. Compete à União instituir os seguintes impostos: I. imposto sobre a importação e exportação de produtos; II. imposto sobre a renda e proventos de qualquer natureza. $\$ 11^{\circ}$. É facultado ao Poder Executivo, atendidas as condições e os limites estabelecidos em lei, alterar as alíquotas do imposto enumerado no inciso $I$.

\$2.․ O imposto sobre a renda e proventos de qualquer natureza, quando incidente sobre os rendimentos do mercado financeiro, poderá ser alterado sem submissão ao disposto nos arts. 150, inciso III, letra " $b$ ", e 165, 5 2.

Art. 154. A União poderá instituir, em caso de guerra externa, impostos extraordinários, compreendidos ou não em sua competência tributária, os quais serão suprimidos, gradativamente, cessadas as causas de sua criação.

Seção $N$

Do imposto dos Estados e do Distrito Federal

Art. 155. Compete aos Estados e ao Distrito Federal instituir imposto sobre operações relativas à circulação de mercadorias e à prestação de serviços. 
\$ 10. 0 imposto previsto neste artigo atenderá ao seguinte: I. será não-cumulativo, compensando-se o que for devido em cada operação relativa à produção, circulação de mercadorias ou prestação de serviços com o montante incidente nas anteriores a favor do mesmo ou de outro Estado ou do Distrito Federal;

II. será seletivo, em função da essencialidade das mercadorias e dos serviços;

III. Resolução do Senado Federal, de iniciativa do Presidente da República ou de um terço dos Senadores, aprovada pela maioria absoluta de seus membros, estabelecerá as alíquotas máximas aplicáveis às operações e prestações internas, interestaduais e de exportação, assim como os limites das isençôes e beneficios fiscais;

IV. em relação às operações e prestações que destinem bens e serviços a consumidor final localizado em outro Estado, adotar-se-á:

a) a aliquota interestadual, quando o destinatário for contribuinte do imposto;

b) a aliquota interna, quando o destinatário não for contribuinte dele;

V. na hipótese da alínea "a"do inciso anterior, caberá ao Estado da localização do destinatário o imposto correspondente à diferença entre a alíquota interna $e$ a interestadual;

$V I$. não incidirá sobre operações que destinem ao exterior produtos industrializados;

VII. poderá a lei complementar estabelecer hipóteses de substituição tributária por antecipação;

VIII. cabe à lei complementar definir o regime jurídico nacional do imposto mencionado neste artigo.

\section{Seção $V$}

Do imposto dos Municipios

Art. 156. Compete aos municipios e ao Distrito Federal instituir imposto sobre a propriedade predial e territorial urbana e rurale sobre veiculos automotores. 
Parágrafo único. Cabe à lei complementar fixar as alíquotas mínimas e máximas do imposto previsto neste artigo.

\section{Seção VI}

Da repartição das receitas tributárias

Art. 157. Pertencem à União $40 \%$ do produto da arrecadação dos impostos previstos nos arts. 155 e 156.

Art. 158. Pertencem aos Estados 35\% do produto da arrecadação dos impostos a que se referem os arts. 153, II e 156. Art 159. Pertencem aos Municípios 25\% do produto da arrecadação dos impostos a que se referem os arts. 153, I e II, e 155. Art. 160. Pertence ao Distrito Federal, na proporção da repartição fiscal, percentual idêntico ao dos Municípios.

Art. 161. Cabe à lei complementar definir os critérios para a participação reciproca mencionada nos arts. 157 a 160, devendo a unidade da Federação em que seja recolhido imposto de competência das demais unidades, ter, no mínimo, $50 \%$ do produto da arrecadação transferida aplicados em seu território. Parágrafo único. As unidades federativas poderão condicionar a entrega da participação recíproca ao pagamento de seus créditos de qualquer natureza.

Art 162. A União, os Estados, o Distrito Federal e os Municípios deverão repassar a parcela correspondente às demais entidades federativas até quinze dias de sua recepção.

Artigo 195 A seguridade social será financiada por toda a sociedade, de forma direta e indireta, nos termos da lei, mediante recursos provenientes dos orçamentos da União, dos Estados, do Distrito Federal e dos Municipios, e da contribuição social prevista no artigo 149".

\section{Justificação} titucional.

O anteprojeto objetivou simplificar a estrutura tributária cons-

Para não alterar a numeração, mantive a seqüência de artigos do texto atual (145 a 162), embora não tenha feito a adaptação do 
art. 195 e de outros relacionados com o sistema. Farei as adaptações, no futuro, se a proposta tiver aceitação.

De rigor, mantenho as cinco espécies tributárias, reduzo os impostos para quatro, além de manter a competência residual limitada aos impostos extraordinários. As contribuições especiais são reduzidas a uma contribuição social incidente sobre as transações financeiras em até $1 \%$ sobre o valor da transação. As taxas são cobradas apenas para serviços públicos e não mais para exercicio do poder de polícia. Procurei separar sua conformação daquela própria do preço público. Por fim, os empréstimos compulsórios serão instituídos apenas nos casos de guerra e calamidade pública.

No capítulo da partição de receitas tributárias, tornei todas as unidades federativas participantes do contraído elenco de tributos.

Serve, esta primeira minuta, como um boneco para o início das discussões e fica, de certa forma, vinculada - o espectro um pouco mais alargado - à proposta que fiz na Comissão de Finanças da Câmara dos Deputados, lembrando que a função do IOF foi substituída pela maior elasticidade que outorgo, na proposta, ao imposto de renda na fonte para o sistema financeiro. 